Marcel Labine, est né à Montréal le 25 février 1948. Il fait ses études de premier cycle à la Faculté des Lettres de l'Université de Montréal. Depuis 1971, il est professeur de littérature dans un collège de Montréal. De 1979 à 1983 il collabore au magazine culturel Spirale. De décembre 1985 à avril 1990, il est membre du comité de rédaction de la collection «Première ligne» à la revue La Nouvelle Barre du Jour.

\title{
Oeuvres:
}

Lisse, poèmes (Revue Les Herbes Rouges, no. 31, 1975); L'Appareil, po丸̀mes et prose, en collaboration avec Normand de Bellefeuille (Revue Les Herbes Rouges, no. 49, 1976); Les Lieux domestiques, pò̀mes (Revue Les Herbes Rouges, no. 49, 1977) Les Allures de la mort, prose (Revue Les Herbes Rouges, no. 73, 1979); La Marche de la dictée, prose (Revue Les Herbes Rouges no. 83, 1980; Des Trous dans l'anecdote, prose (Revue Les Herbes Rouges no. 87, 1981); Les Matières de ce siècle, prose, en collaboration avec Normand de Bellefeuille, (Revue Les Herbes Rouges no. 130, 1984) Papiers d'épidémie, poésie (Editions Les Herbes Rouges, 1987): prix du Gouverneur Général du Canada 1988 en poésie; Musiques, dernier mouvement, prose (La Nouvelle Barre du Jour, no. 213, 1987): prix d'excellence pour le meilleur texte de fiction, décerné par l'association des éditeurs de périodiques culturels québécois (AEPCQ).

\section{Territoires Fétiches: deuxième avancée (extraits)}

La patience du corps, c'est déjà et encore la pensée

(Maurice Blanchot, L'Ecriture du désastre)

5. Un visage de femme peuple le creux de tes paumes. Il ne réclame rien, il est sans loi, sans famille. Il pose avec lenteur un regard étonné sur tes mâchoires tendues comme si soudain ta tête emprisonnait en elle les rites les plus sauvages. Au fil des jours tu laisseras loin de toi, sur des rivages de pierre, les vieilles mythologies, celles qui détruisent ta marche, celles qui coupent les fils. Le passé ne sert à rien; tout au plus encombre-t-il la mémoire et rend-il coupable. Le visage d'une femme te regarde longuement comme s'il attendait avec une patience sans mesure que tu lâches, que tu oublies les territoires fétiches, la ferraille et le sang plaqué aux murs. Il te faudra apprendre, visage bien en mains, bras et jambes confondus dans la moiteur des draps, à devenir païen. 


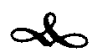

7. Des ongles de femme touchent une à une tes vertèbres en saillie et tu frissonnes comme si soudain tu te retrouvais nu sur les banquises du Nord. Une onde t'a fait tressaillir. Cela ressemble au jour de ta naissance, rouge et vociférant dans la clarté des choses. Mais ici, tu es sans voix. Tu trembles tel les arbres sous le coup de la hache, tel les peaux de tambours au milieu des tropiques. Il y a dans ton échine, sous la promenade des ongles, l'harmonie des musiques qui résonnent au tympan. Tu n'es qu' une conque, que cet espace creux qui se moule aux rumeurs du dehors. Tu oscilles et tu vibres comme les vitraux de palais quand passe le sabot des bêtes. Tu es sans âme, tu n'es qu'un lobe que des lèvres viennent lécher, que des dents viennent mordre tout à coup. Tu n'es parfaitement qu'un effet de la langue.

12. Tu fermes les paupières et, paumes ouvertes le long de tes hanches, tu guettes la métamorphose. Tu attends ce moment où l'on ne reconnait plus rien de sa langue ni de la tribu. Tu souhaites, comme le dernier des luxes, que le réel si proche bascule dans les mers comme les déchets qu' on jette aux grands oiseaux criards qui se battent entre eux. Tu vois cette lutte sans fin, cette mythologie de mort, tous ces bruits où l'on compte les cadavres comme autant de trophées. Tu souhaites le désert, la banquise, la brousse, n' importe quel lieu soustrait aux rituels. Ton désir est païen, inhumain, végétal. Il est là, dans un lit, près d'une femme qui connaît les visages multiples des fétiches que ses lèvres récitent à voix basse. Tu te penches vers elle afin de tout entendre de cet écho du monde.

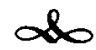

